\title{
Preventing Inadvertent Perioperative Hypothermia
}

Alexander Torossian, Anselm Bräuer, Jan Höcker, Berthold Bein, Hinnerk Wulf, Ernst-Peter Horn

\section{SUMMARY}

Background: $25-90 \%$ of all patients undergoing elective surgery suffer from inadvertent postoperative hypothermia, i.e., a core body temperature below $36^{\circ} \mathrm{C}$. Compared to normothermic patients, these patients have more frequent wound infections (relative risk [RR] 3.25, 95\% confidence interval [Cl] 1.35-7.84), cardiac complications (RR 4.49, 95\% Cl 1.00-20.16), and blood transfusions (RR 1.33, 95\% Cl 1.06-1.66). Hypothermic patients feel uncomfortable, and shivering raises oxygen consumption by about $40 \%$.

Methods: This guideline is based on a systematic review of the literature up to and including October 2012 and a further one from November 2012 to August 2014. The recommendations were developed and agreed upon by representatives of five medical specialty societies in a structured consensus process.

Results: The patient's core temperature should be measured 1-2 hours before the start of anesthesia, and either continuously or every 15 minutes during surgery. Depending on the nature of the operation, the site of temperature measurement should be oral, naso-/oropharyngeal, esophageal, vesical, or tympanic (direct). The patient should be actively prewarmed 20-30 minutes before surgery to counteract the decline in temperature. Prewarmed patients must be actively warmed intraoperatively as well if the planned duration of anesthesia is longer than 60 minutes (without prewarming, 30 minutes). The ambient temperature in the operating room should be at least $21^{\circ} \mathrm{C}$ for adult patients and at least $24^{\circ} \mathrm{C}$ for children. Infusions and blood transfusions that are given at rates of $>500 \mathrm{~mL} / \mathrm{h}$ should be warmed first. Perioperatively, the largest possible area of the body surface should be thermally insulated. Emergence from general anesthesia should take place at normal body temperature. Postoperative hypothermia, if present, should be treated by the administration of convective or conductive heat until normothermia is achieved. Shivering can be treated with medications.

Conclusion: Inadvertent perioperative hypothermia can adversely affect the outcome of surgery and the patient's postoperative course. It should be actively prevented.

\section{Cite this as:}

Torossian A, Bräuer A, Höcker J, Bein B, Wulf H, Horn EP:

Clinical practice guideline: Preventing inadvertent perioperative hypothermia.

Dtsch Arztebl Int 2015; 112: 166-72. DOI: 10.3238/arztebl.2015.0166

Clinic of Anesthesiology and Intensive Care Medicine, UKGM Giessen and Marburg, Marburg:

Prof. Dr. med. Torossian, Prof. Dr. med. Wulf

Center for Anesthesiology, Emergency and Intensive Care Medicine, University Medical Center Göttingen: Prof. Dr. med. Bräuer

Department of Anesthesiology and Intensive Care Medicine, University Medical Center Schleswig-Holstein, Campus Kiel: PD Dr. med. Höcker

Department of Anaesthesia and Surgical Critical Care, Asklepios Clinic St. Georg, Hamburg:

Prof. Dr. med. Bein

Department of Anaesthesiology and Intensive Care Medicine, Regio Kliniken Pinneberg: PD Dr. med. Horn ypothermia (body temperature $<36{ }^{\circ} \mathrm{C}$ ) is present in the postoperative period in $26 \%$ to $90 \%$ of all patients who have undergone elective surgery (1). The risk of hypothermia is particularly high in patients over 60 years of age with poor nutritional status and pre-existing disease that impairs thermoregulation (e.g., diabetes mellitus with polyneuropathy) and in those who have had major or lengthy surgery. Lower temperatures in the operating room also increase the risk of hypothermia: the lower the temperature, the higher the risk.

If hypothermia does occur, the relative risk of severe complications such as impaired wound healing is 3.25 (95\% confidence interval [CI] 1.35 to 7.84 ) compared to normothermia; for cardiac disorders it is $4.49(95 \%$ CI 1.00 to 20.16), and for increased bleeding with blood transfusions it is 1.33 (95\% CI 1.06 to 1.66) (2). Against this background, the existing evidence on preventing, recognizing, and treating perioperative hypothermia demands to be turned into recommendations for practice. This was the objective of the first Germanlanguage interdisciplinary S3 guideline, developed under the auspices of the German Society of Anaesthesiology and Intensive Care Medicine (DGAI, Deutsche Gesellschaft für Anästhesiologie und Intensivmedizin), together with the German Surgical Society (DGCH, Deutsche Gesellschaft für Chirurgie), the German Society of Pediatric Surgery (DGKIC, Deutsche Gesellschaft für Kinderchirurgie), the German Society for Specialist Nursing and Ancillary Medical Staff (DGF, Deutsche Gesellschaft für Fachkrankenpflege und Funktionsdienste), and the Austrian Society of Anesthesiology, Resuscitation, and Intensive Care Medicine (ÖGARI, Österreichische Gesellschaft für Anästhesiologie, Reanimation und Intensivmedizin) (Box). This article presents the main principles of the guideline. For further detail, the reader is referred to the long version ([3], in German).

\section{Methods}

The development of this guideline was initiated in Marburg and the working process was moderated by Prof. Ina Kopp of the Association of Scientific Medical Societies in Germany (AWMF, Arbeitsgemeinschaft der Wissenschaftlichen Medizinischen Fachgesellschaften). The guideline group consisted of 14 experts, nine of them with responsibility as section authors 
(Bein, Bräuer, Höcker, Horn, Ittner, Torossian, Schmittenbecher, Welk, Weyland) (Box).

At the constitutive consensus conference, the coordinator presented an initial literature search, and through a nominal group process the guideline group agreed search terms for the literature search on PubMed, APC Journal Club, and CINAHL, and also agreed five key clinical questions:

- What is the normal core body temperature of a surgical patient; when and where should it be reliably measured in the perioperative period?

- What are the risk factors for the occurrence of perioperative hypothermia?

- What are the consequences of perioperative hypothermia?

- What warming techniques exist to reduce perioperative hypothermia?

- How should the guideline be implemented?

The coordinator was commissioned to undertake guideline research/synopsis in order to allow the group to adapt existing recommendations ("guideline adaptation"). The search covered GIN, AHRQ (National Guidelines Clearinghouse), the Cochrane Library, and Medline via PubMed including a search by hand. Four international guidelines were identified $(2,4-6)$ and evaluated in accordance with DELBI domain 3 (7) (eFigure 1). The NICE Clinical Guideline 65 of 2008 (2) was given the highest evaluation score and thus became the primary source guideline. The section entitled "Risk factors" was taken over in shortened form from this guideline. Next, the coordinator carried out a systematic research update ("de novo evaluation of evidence") for the years 2006 to 2012 for the sections entitled "Prewarming," "Intraoperative warming", and "Shivering" using MeSH terms in Medline (eFigure 2, sample search). Only patient studies were included (no case reports). Publications in English, German, and French were included (formal selection). From the literature identified in this way, a further selection was made on the basis of title, abstract, and full text with reference to answering the key questions listed above (content selection). Because the sections "Normal body temperature" and "Measuring body temperature" are not adequately covered in the NICE guideline, a previous publication by the coordinator (8) was updated in a similar fashion. Out of a total of 4865 publications identified, 243 relevant ones were selected and passed to the chapter responsible authors as topicspecific literature packages to be individually evaluated using structured checklists (modified according to SIGN [9]). The results of the evaluation were summarized in evidence tables.

This short version of the guideline cites only selected publications that underpin the main recommendations. The final version of the recommendations developed by the authors was produced in the course of three meetings of the steering group, the last of which took place on 22 March 2013. This was the basis, including the draft full text, on which all members of the guideline group voted in an online Delphi round, using

\section{Members of the guideline group responsible for development of the guideline "Preventing inadvertent perioperative hypothermia"}

- German Society of Anaesthesiology and Intensive Care Medicine (DGAI, Deutsche Gesellschaft für Anästhesiologie und Intensivmedizin)

- Prof. Dr. med. Berthold Bein (Hamburg) ${ }^{*_{1} *_{2}}$

- Prof. Dr. med. Anselm Bräuer (Göttingen) ${ }^{* 1 * 2}$

- PD Dr. med. Jan Höcker (Kiel) ${ }^{\star 1 * 2}$

- PD Dr. med. Ernst-Peter Horn (Pinneberg) ${ }^{*_{1} *_{2}}$

- PD Dr. med. Karl-Peter Ittner (Regensburg) ${ }^{\star 1 * 2}$

- Prof. Dr. med. Alexander Torossian (Marburg) ${ }^{*_{1} * 2}$ - Coordinator

- Prof. Dr. med. Wolfgang Weyland (Düsseldorf) ${ }^{* 2}$

- Prof. Dr. med. Hinnerk Wulf (Marburg)

- German Surgical Society (DGCH, Deutsche Gesellschaft für Chirurgie)

- Prof. Dr. med. Ernst Klar (Rostock)

- German Society of Pediatric Surgery (DGKIC, Deutsche Gesellschaft für Kinderchirurgie)

- Prof. Dr. med. Peter Schmittenbecher (Karlsruhe) ${ }^{* 2}$

- German Society for Specialist Nursing and Ancillary Medical Staff (DGF, Deutsche Gesellschaft für Fachkrankenpflege und Funktionsdienste) - Tillmann Müller-Wolff (Reutlingen)

- Ina Welk (Kiel)²

- Austrian Society of Anesthesiology, Resuscitation, and Intensive Care Medicine (ÖGARI, Österreichische Gesellschaft für Anästhesiologie, Reanimation und Intensivmedizin)

- PD Dr. med. Oliver Kimberger (Wien)

- Swiss Society of Anesthesiology and Resuscitation (SGAR, Schweizerische Gesellschaft für Anästhesiologie und Reanimation) - Prof. Dr. med. Robert Greif (Bern) - not mandated

${ }^{* 1}$ member of steering group; ${ }^{* 2}$ authors with chapter responsibility; bold: lead author

a structured questionnaire. An updated literature search in PubMed for the period 1 November 2012 to $19 \mathrm{Au}-$ gust 2014 yielded 12 publications, three of which were included as relevant (Table 1).

The evidence underlying the present guideline is presented in a manner based on the evidence categories of the Oxford Centre for Evidence Based Medicine (10). The strength of each recommendation takes into account clinical practicability in relation to the methodologically evaluated evidence ("considered judgment") (Figure). The scheme employed in the guideline for deriving recommendation grades from evidence levels is shown in simplified form in Table 1. The recommendations are formulated by analogy to their grading as: strong recommendation, "should" (A); 


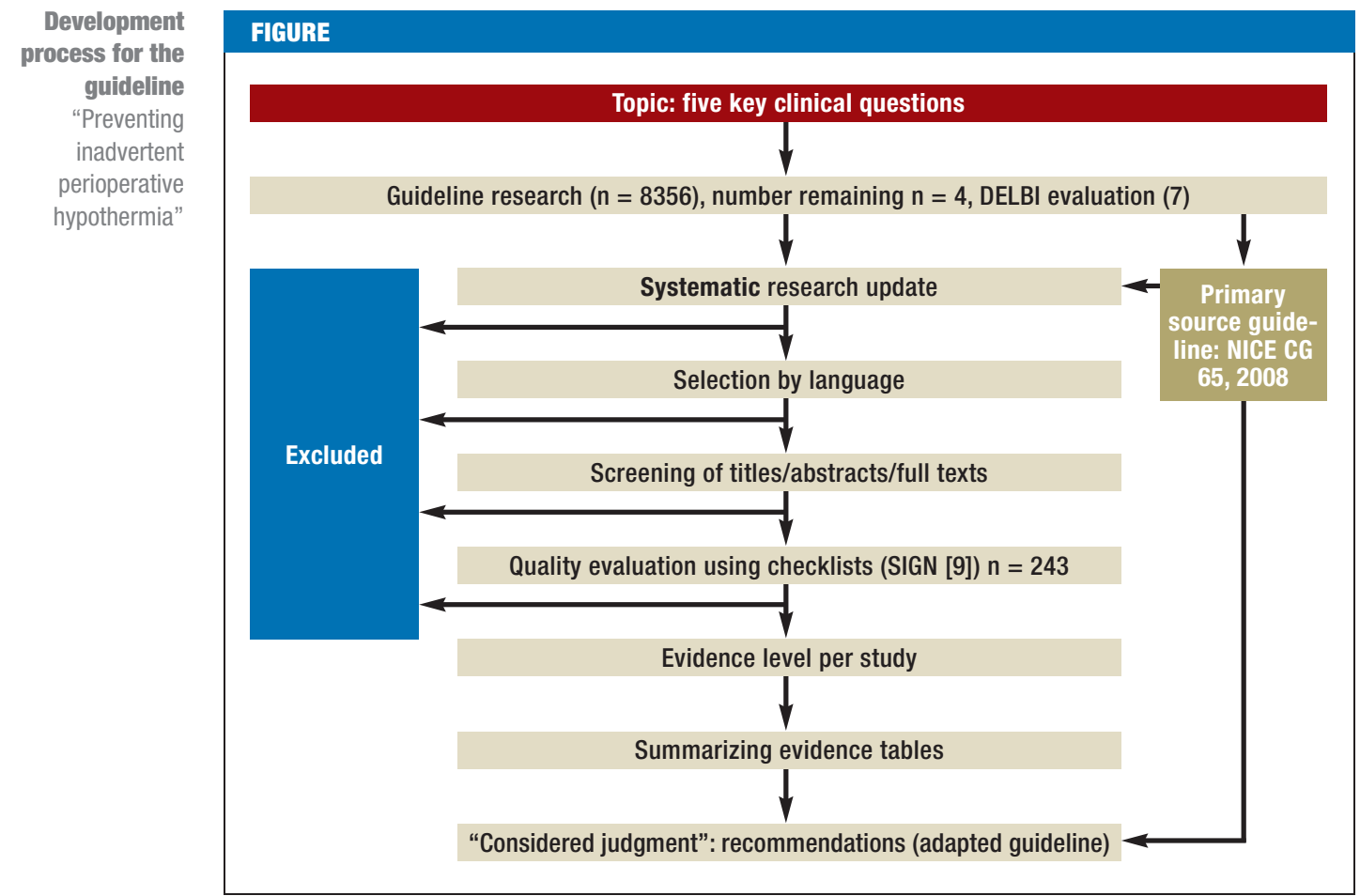

weak recommendation, "probably should" (B); no recommendation, "may" (optional course of action, 0 ). Negative recommendations are expressed using the word "not." The guideline was supported financially by the DGAI and the guideline group had editorial independence. The authors and participants in the consensus process worked on a voluntary basis and submitted a written declaration of any conflicts of interests they had, in particular those relating to industry. Full procedural details are provided in the methods section of the full guideline (11).

\section{Normal core body temperature and definition of hypothermia}

As early as 1860, the Leipzig physician Carl Wunderlich, using mercury thermometers, established the paradigm of the mean normal body temperature of $37^{\circ} \mathrm{C}$, on the basis of axillary temperature measurements in thousands of patients (12). The temperature chart still in routine clinical use today was introduced by Wunderlich to monitor the course of disease in patients in hospital. The paradigm was confirmed by modern thermometers that measure temperature at sites closer to the core of the body. Today it is also known that the core temperature of the body is subject to a biorhythm, fluctuating according to the time of day and the time of year. The whole of the body's metabolism, by producing heat, contributes to maintaining the temperature of the body, and it is affected by physical activity and by hormones.

Because of this, a normal temperature range can be defined that lies between 36 and $37.5{ }^{\circ} \mathrm{C}$ (13). It follows, as is recognized in international guidelines, that a core body temperature of $36{ }^{\circ} \mathrm{C}$ should be regarded as the threshold for hypothermia.

\section{Epidemiological and pathophysiological aspects of perioperative hypothermia}

A Europe-wide survey on the practice of intraoperative patient warming revealed that only $40 \%$ of all patients under general anesthesia were warmed intraoperatively, and temperature was measured in only $20 \%$. Among patients under regional anesthesia, only $20 \%$ were warmed and only $6 \%$ had their temperature measured (14). From this, it must be concluded that the need to prevent inadvertent perioperative hypothermia has insufficient hold in the minds, not only of anesthetists and nurses, but also in those of surgeons and medical ancillary staff.

After the induction of general anesthesia, the body's "thermostat" in the hypothalamus is "set" to a lower temperature. Cooling of the patient is the result mainly of redistribution of heat after the induction of anesthesia together with the body's release of heat (net heat loss). The physical exchange of heat between the body and its environment occurs by means of four mechanisms:

- Radiation, accounting for about $50 \%$ to $70 \%$

- Convection (heat loss via the ambient air stream), accounting for about $15 \%$ to $25 \%$

- Evaporation via skin and mucosa, accounting for $5 \%$ to $20 \%$

- Conduction (heat loss by direct contact between surfaces), accounting for about $3 \%$ to $5 \%$. 


\begin{tabular}{|c|c|c|c|c|}
\hline \multirow{2}{*}{$\begin{array}{l}\text { Evidence level } \\
\text { (Oxford) }\end{array}$} & \multicolumn{2}{|c|}{ Simplified definition of sources } & \multirow{2}{*}{$\begin{array}{l}\text { Recommendation } \\
\text { grade }\end{array}$} & \multirow{2}{*}{ Description } \\
\hline & Treatment & Diagnosis & & \\
\hline I & Randomized controlled trials & Validating cohort studies & A ("should") & Strong recommendation \\
\hline$\|$ & Controlled studies without randomization & Explorative cohort studie & B ("probably should") & Weak recommendation \\
\hline III or IV & \multicolumn{2}{|c|}{ Observation studies, expert opinion } & 0 ("may") & No recommendation \\
\hline & \multicolumn{2}{|c|}{ Structured consensus formation—clinical judgment } & Expert consensus & $\begin{array}{l}\text { Consensus on "good } \\
\text { clinical practice" }\end{array}$ \\
\hline
\end{tabular}

For more detail on perioperative thermoregulation, readers are referred to the long version of the guideline (3).

\section{Diagnosing hypothermia: measuring core body temperature perioperatively}

Core body temperature is a vital sign. To prevent hypothermia and to recognize it early, the patient's core temperature should be measured before he or she is moved into the OR ( 1 to 2 hours before the onset of anesthesia) and also on arrival in the OR (expert consensus). Intraoperatively, continuous temperature monitoring is recommended. If temperature is measured intermittently, this should be done at least every 15 minutes (expert consensus). This requires that all anesthesia workstations are readily equipped with the functionality to measure body temperature (expert consensus), although current regulations require this only for anesthesia workstations used for anesthesia in children (15).

\section{Measurement methods and measurement site for perioperative core body temperature}

In practice, the measurement of core body temperaturedepending on what method is used and where the measurement is made-is subject to considerable error. Perioperatively, core temperature should so far as possible be measured at the same site and using the same method (expert consensus). Invasive measurement of core temperature in the pulmonary artery via a Swan-Ganz catheter is regarded as the reference site. Of the less invasive measurement sites, the oral (sublingual) is currently regarded as the most reliable (evidence level [EL] Ib, [cf. reference 16], recommendation grade A). Temperature measurements at this site are easy to carry out, reproducible, and correlate well with the core body temperature; and they can be performed both pre-, post-, and intraoperatively (17). Other less invasive methods that are suited for perioperative usedepending on the surgical region-are naso-/oropharyngeal, esophageal, vesical, or direct tympanic membrane temperature measurement (EL IIa, [16], recommendation grade $\mathrm{A}$ ).
Quick infrared ear temperature measurement is inaccurate, since it usually records only the temperature of the external auditory canal, not that of the tympanic membrane. This results in large deviations of 1 to $2{ }^{\circ} \mathrm{C}$ from the core temperature; it also yields values that differ between users. For this reason, this method cannot be recommended (EL Ib, [16], recommendation grade $\mathrm{A}$ ).

\section{Risk factors for inadvertent perioperative hypothermia}

As early as the 1950s, the English physician Sir George Pickering expressed that the most effective way of cooling a human being was to anesthetize him or her. This side effect of anesthesia means that basically any patient under general or regional anesthesia develops hypothermia, though the extent of the hypothermia is affected by other factors relating to the individual patient, type of anesthesia, surgery, drugs used, and to the environment. The following all indicate increased risk for the development of perioperative hypothermia:

- Older age (60 years and over)

- Low body weight/poor nutritional status

- Pre-existing conditions that impair thermoregulation (e.g., diabetes mellitus with polyneuropathy, hypothyroidism, ingestion of sedatives or psychoactive drugs)

- An ASA (American Society of Anesthesiologists) risk class higher than I (ASA risk classes classify postoperative mortality; risk increases exponentially with class number).

- Pre-existing hypothermia (existing before the surgery) is also an independent risk factor for further cooling of the patient (3).

- If general anesthesia is combined with regional anesthesia close to the spinal cord (especially if this is in the form of high spinal blockade with corresponding sympatholysis), the risk of intraoperative cooling of the patient rises further. A duration of anesthesia greater than 2 hours and intraoperative infusion of large volumes of unwarmed solutions or transfusion of cold red blood cell concentrates $\left(4^{\circ} \mathrm{C}\right)$ also increase inadvertent hypothermia. 
- The nature, extent, and duration of surgery are surgery-related risk factors for the development of hypothermia. So is the intraoperative use of large volumes of unwarmed irrigation fluids (3).

- The temperature of the OR also has a decisive effect on the patient's postoperative body temperature, which is significantly higher in a warmer OR $\left(21\right.$ to $\left.24^{\circ} \mathrm{C}\right)$ than in a colder one $(18$ to $21{ }^{\circ} \mathrm{C}$ ) (18). For this reason, an ambient temperature in the $\mathrm{OR}$ of at least $21^{\circ} \mathrm{C}$ is recommended for adults and at least $24{ }^{\circ} \mathrm{C}$ for children (EL II, [18], expert consensus).

\section{Complications of inadvertent perioperative hypothermia}

The most severe complications associated with inadvertent perioperative hypothermia are cardiac events (EL Ia, [2, 3, 19]) such as cardiac arrhythmia and myocardial infarction (20), coagulation disorders with increased bleeding and increased transfusion requirement (EL Ia, [21]), impaired wound healing (EL Ia, [2, $3]$ ), wound infections (22), and pressure ulcers.

In addition to these effects, the effect of anesthetic agents is prolonged (23) and serum potassium concentration falls. Subcutaneous partial oxygen pressure is lowered in the region of the wound by peripheral vasoconstriction due to cold (24). This also impairs the phagocytic activity of oxygen-dependent polymorphonuclear granulocytes and thus elevates the risk of postoperative wound infection.

Shivering can occur in postoperative hypothermia as the effect of the anesthetic starts to wear off. This is regarded as a physiological mechanism of heat production, but is experienced by the patient as very unpleasant and increases oxygen consumption by about $40 \%$ (25).

To summarize, it may be stated that perioperative hypothermia has a negative influence on surgical outcome and the postoperative course, even increasing the length of hospital stay and the cost of treatment $(2,3)$. Subjectively, the patient feels uncomfortable.

\section{Possible preventive measures Warming the patient before surgery ("prewarming")}

The concept of prewarming the patient is based on the simplified model in which the peripheral parts of the patient's body are regarded as a "thermal buffer." When the patient is awake, there is a natural temperature gradient between the core and the periphery (skin) of about 5 to 8 ${ }^{\circ} \mathrm{C}$. Warming the surface of the body reduces this gradient and increases the overall heat content of the body, so that the initial drop in temperature due to redistribution after the induction of anesthesia is reduced.

This active prewarming (e.g., convective) before induction of general anesthesia is very effective in preventing perioperative hypothermia (EL Ia, [26], recommendation grade A). The prewarming should last for 10 to 30 minutes (EL Ib, [27-29], recommendation grade A). Patients should also be actively warmed before epidural or spinal anesthesia (EL Ib, [28], recommendation grade $\mathrm{B}$ ).

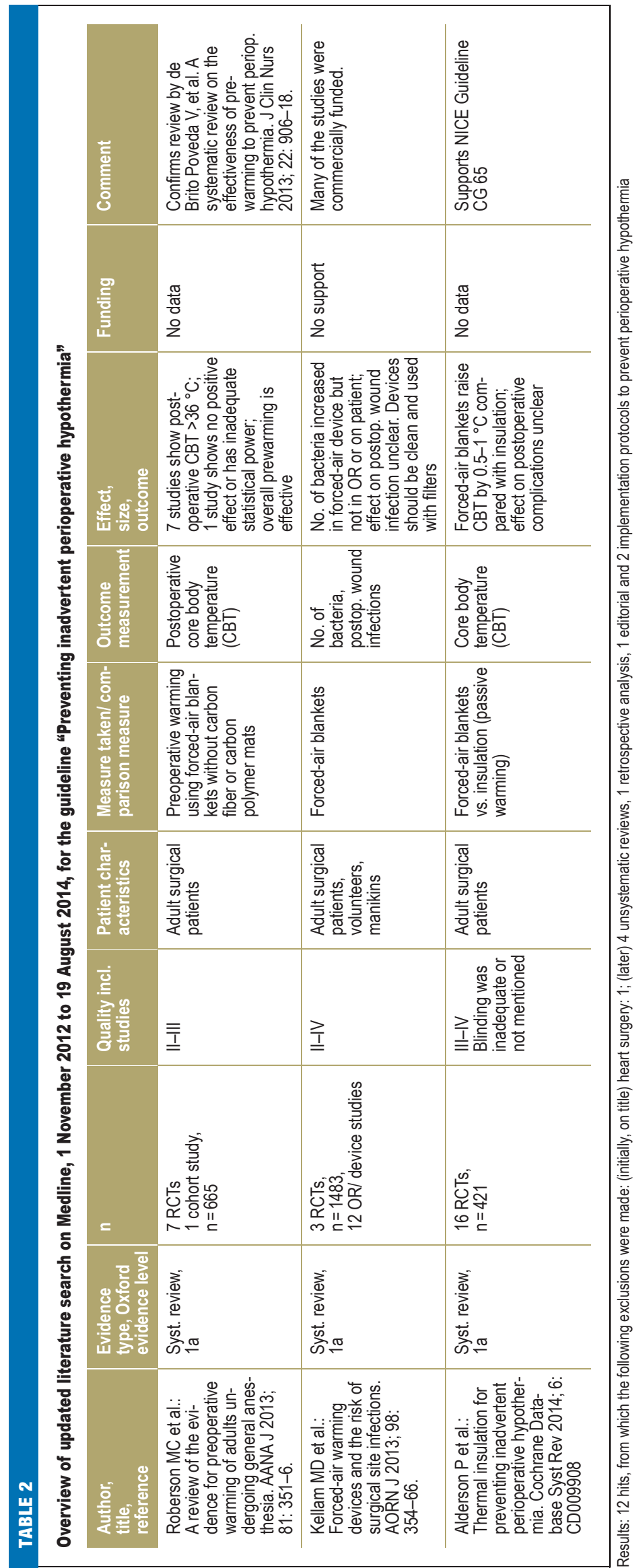




\section{Active warming of the patient during surgery}

Convective heating using a forced-air warming blanket is very effective, since most of the heat lost by the patient is lost through radiation and convection. Through the blanket, warmed air flows over the patient's skin. The warming devices should be cleaned and used with filters according to their manufacturers' instructions, as they can harbor bacteria (30). A further rise in warming efficacy can be achieved by combining intraoperative patient warming with prewarming (31).

During the intraoperative period-that is, from induction to the end of anesthesia - all patients who are scheduled to receive anesthesia for longer than 30 minutes should be actively warmed (EL Ia, [2, 3], recommendation grade $\mathrm{A}$ ). In patients who have been prewarmed, active intraoperative warming is not required if the duration of anesthesia is less than 60 minutes (expert consensus).

Conductive warming methods (transfer of heat by direct contact) can be used for heat retention as an alternative to convective methods. Blankets laid on top of the body should be used for this. Heating blankets laid under the patient's back should only be used to supplement those on top (EL Ia, [32, 33], recommendation grade B).

\section{Passive warming}

Thermal insulation is an external (passive), effective way of reducing radiating and convective heat loss via the skin. Various materials reduce heat loss by up to $30 \%$ (34). In addition to active warming, the largest possible (not actively warmed) area of the body should be covered (insulated) (EL III, expert consensus). Insulation alone does not usually suffice to maintain normothermia intraoperatively. A recent Cochrane Review confirms that only active warming increases body temperature by 0.5 to $1{ }^{\circ} \mathrm{C}$ compared to warming by insulation (35).

\section{Warming infusions and blood products}

Administration of large volumes of cold infusion solutions or blood products reduces core body temperature (36), and therefore intraoperative warming of infusions and blood products given at infusion rates above $500 \mathrm{~mL} / \mathrm{h}$ should also be implemented (expert consensus). Warming infusion solutions in an infusion warmer ("in-line warming") is very effective and should be employed (EL II, [2, 3], recommendation grade B). In cases where there is little fluid exchange, the use of infusion warmers alone is not enough to maintain normothermia (37).

\section{Warming irrigation solutions}

Intraoperative irrigation fluids should be prewarmed to 38 to $40{ }^{\circ} \mathrm{C}(\mathrm{EL} \mathrm{Ib},[3,38]$, recommendation grade $\mathrm{A})$.

\section{Special patient groups: children}

Infants have a higher core temperature than older children, and because their thermoregulation mechanisms are less mature and they have a higher body area to body weight ratio, they cool down more quickly (14). Normal core temperature in children up to 5 years is 36.5 to $38.0{ }^{\circ} \mathrm{C}$ (EL IIb, [39]). Up to the age of 2, rectal measurement of core temperature is recommended (EL IIb, [39], recommendation grade A).

\section{Postoperative period and management of shivering}

Shivering after surgery occurs in $10 \%$ to $60 \%$ of patients after general (40) and regional anesthesia (29) and should be treated by active warming. Supplementary medical therapy can be given in the form of clonidine or pethidine, for example, though this is an off-label use as neither one of these drugs is approved for this use (EL IIa, [40], recommendation grade A).

\section{Steps to be taken by the postoperative care unit}

After the end of anesthesia, the physiological thermoregulation mechanisms rapidly return. On admission to the unit providing postoperative care (recovery room, intermediate care, intensive care unit, normal ward), the patient's core temperature should be measured (expert consensus). Patients who are hypothermic postoperatively should be actively warmed until they reach normothermia (expert consensus), during which time their core temperature should be measured regularly, e.g., every 15 minutes (expert consensus).

\section{Patient information, guideline implementation, monitoring of outcome of heat management}

Patients should receive information before surgery about the risk of inadvertent perioperative hypothermia (causes and effects, preventive measures, and treatment; expert consensus). To implement the guideline, a perioperative checklist is recommended (expert consensus). Every 3-6 months, the incidence of postoperative hypothermia (patient core body temperature on arrival in the recovery room) should be monitored by means of a sample survey.

\section{Conflict of interest statement}

Professor Torossian has received consultancy fees from Mölnlycke, GE, and Arizant, and has been reimbursed for conference, travel, and accommodation expenses by Arizant and Mölnlycke. He has received funding from Mölnlycke and $5 \mathrm{Med}$ for a research project initiated by himself.

Professor Wulf has received third-party funding for carrying out clinical studies for Mölnlycke and lecture fees from Smith Medical and Arizant.

Dr. Höcker has had conference attendance fees and travel and accommodation expenses reimbursed by $3 \mathrm{M}$. He has received lecture fees from $3 \mathrm{M}$, Mölnlycke and The $37^{\circ}$ Company. He has received equipment from $3 \mathrm{M}$ for a research project initiated by himself.

Prof. Bräuer receives consultancy fees from 3M. He has received fees for the preparation of scientific meetings from 3M and LMA Deutschland. He has had conference attendance fees and travel and accommodation expenses reimbursed by $3 \mathrm{M}$. He has also received fees for carrying out clinical studies for LMA Deutschland.

Professor Bein has received consultancy fees and reimbursement of travel and accommodation expenses, fees for the preparation of scientific meetings, and funding for a research project initiated by himself from 3M Deutschland.

Dr. Horn declares that no conflict of interest exists.

Manuscript received on 29 June 2014, revised version accepted on 17 December 2014.

Translated from the original German by Kersti Wagstaff, MA. 


\section{REFERENCES}

1. Moola S, Lockwood C: Effectiveness of strategies for the management and/or prevention of hypothermia within the adult perioperative environment. Int J Evid Based Health 2011; 94: 337-45.

2. NICE: Clinical-Practice-Guideline, the management of inadvertent perioperative hypothermia in adults. National Collaborating Centre for Nursing and Supportive Care commissioned by National Institute for Health and Clinical Excellence (NICE). http://guidance.nice.org.uk/CG65 (last accessed on 23 January 2015).

3. S3 Leitlinie: „Vermeidung von perioperativer Hypothermie“ 2014. www. awmf.org/leitlinien/detail/I/001-018.html (last accessed on 9 May 2014).

4. Joanna Briggs Institute: Strategies for the management and prevention of hypothermia within the adult perioperative environment. Best Practice 2010; 14: 1-4. connect.jbiconnectplus.orgNiewSourceFile.aspx?0= 5393 (last accessed on 22 May 2013).

5. Forbes SS, Eskicioglu $C$, Nathens $A B$, et al.: Evidence-based guidelines for prevention of perioperative hypothermia. J Am Coll Surg 2009; 209 492-503.

6. Hooper VD, Chard R, Clifford T, et al.: ASPAN's evidence-based clinical practice guideline for the promotion of perioperative normothermia: second edition. J Perianesthes Nurs 2010; 25: 346-65.

7. Arbeitsgemeinschaft der Wissenschaftlichen Medizinischen Fachgesellschaften (AWMF) und Ärztliches Zentrum für Qualität in der MJedizin (ÄZQ) (Hrsg.): Deutsches Leitlinien-Bewertungs-Instrument (DELBI): Leitlinienbewertung. www.leitlinien.de/leitlinienmethodik/leitlinienbewer tung/delbi (last accessed on 22 May 2013).

8. Torossian A: Intraoperative temperature management. Anasthesiol Intensivmed Notfall Schmerzmed 2008; 43: 397-9.

9. Scottish Intercollegiate Guidelines Network: A Guideline developers handbook. SIGN publication No. 50, 2001. www.sign.ac.uk/guidelines/ fulltext/50/index.html (last accessed on 1 September 2012).

10. Philipps B, Ball C, Sackett D, et al.: Levels of evidence and grades of recommendations. Oxford: Oxford Centre for Evidence-Based Medicine 2009. www.cebm.net/levels_of_evidence.asp (last accessed on 25 September 2012).

11. S3 Leitlinie: „Vermeidung von perioperativer Hypothermie“ 2014. Leitlinien-Methodenreport. awmf.org/leitlinien/aktuelle-leitlinien.html (last accessed on 9 May 2014).

12. Wunderlich C. Das Verhalten der Eigenwärme in Krankheiten. Leipzig 1868.

13. Sund-Levander M, Forsberg C, Wahren LK. Normal oral, rectal, tympanic and axillary body temperature in adult men and women: a systematic literature review. Scand J Caring Sci 2002; 16: 122-8.

14. Torossian A: TEMMP (Thermoregulation in Europe Monitoring and Managing Patient Temperature) Study Group. Survey on intraoperative temperature management in Europe. Eur J Anaesthesiol 2007; 24: 668-75.

15. Beck G, Becke K, Biermann E, et al.: Mindestanforderungen an den anästhesiologischen Arbeitsplatz. Anästh Intensivmed 2013; 54: 39-42.

16. Barnason S, Williams J, Proehl J, et al.: Emergency nursing resource: non-invasive temperature measurement in the emergency department. J Emerg Nurs 2012; 38: 523-30.

17. Höcker J, Bein B, Bohm R, Steinfath M, Scholz J, Horn EP: Correlation, accuracy, precision and practicability of perioperative measurement of sublingual temperature in comparison with tympanic membrane temperature in awake and anaesthetised patients. Eur J Anaesthesiol 2012; 29: 70-4.

18. El-Gamal N, El-Kassabany N, Frank SM, et al.: Age-related thermoregulatory differences in a warm operating room environment. Anesth Analg 2000; 90: 694-8.

19. Scott EM, Buckland R: A systematic review of intraoperative warming to prevent postoperative complications. AORN J 2006; 83: 1090-104, 1107-13.

20. Frank SM, Fleisher LA, Breslow MJ, et al.: Perioperative maintenance of normothermia reduces the incidence of morbid cardiac events: $A$ randomized clinical trial. JAMA 1997; 277: 1127-34.

21. Rajagopalan S, Mascha E, Na J, Sessler DI: The effects of mild perioperative hypothermia on blood loss and transfusion requirement. Anesthesiology 2008; 108: 71-7

22. Melling AC, Ali B, Scott EM, Leaper DJ: Effects of preoperative warming on the incidence of wound infection after clean surgery: a randomised controlled trial. Lancet 2001; 358: 876-80.
23. Heier T, Caldwell JE, Sessler DI, Miller RD: Mild intraoperative hypothermia increases duration of action and spontaneous recovery of vecuronium blockade during nitrous oxide-isoflurane anesthesia in humans. Anesthesiology 1991; 74: 815-9.

24. Sessler DI: Mild perioperative hypothermia. N Engl J Med 1997; 336: 1730-7.

25. Alfonsi P, Nourredine KE, Adam F, Chauvin M, Sessler Dl: Effect of postoperative skin-surface warming on oxygen consumption and the shivering threshold. Anaesthesia 2003; 58: 1228-34.

26. Roberson MC, Dieckmann LS, Rodriguez RE, Austin PN: A review of the evidence for active preoperative warming of adults undergoing general anesthesia. AANA J 2013; 81: 351-6.

27. Horn EP, Bein B, Bohm R, Steinfath M, Sahili N, Hocker J: The effect of short time periods of pre-operative warming in the prevention of peri-operative hypothermia. Anaesthesia 2012; 67: 612-7.

28. Horn EP, Schroeder F, Gottschalk A, et al.: Active warming during cesarean delivery. Anesth Analg 2002; 94: 409-14.

29. Bräuer A, Waeschle RM, Heise D, et al.: Preoperative prewarming as a routine measure. First experiences. Anaesthesist 2010; 59: 842-50.

30. Kellam MD, Dieckmann LS, Austin PN: Forced-air warming devices and the risk of surgical site infections. AORN J 2013; 98: 356-66.

31. Vanni SM, Braz JR, Modolo NS, Amorim RB, Rodrigues GR, Jr.: Preoperative combined with intraoperative skin-surface warming avoids hypothermia caused by general anesthesia and surgery. J Clin Anesth 2003; 15: 119-25.

32. De Witte JL, Demeyer C, Vandemaele E: Resistive-heating or forced-air warming for the prevention of redistribution hypothermia. Anesth Analg 2010; 110: 829-33.

33. Galvão CM, Marck PB, Sawada NO, ClarkAM: A systematic review of the effectiveness of cutaneous warming systems to prevent hypothermia. J Clin Nurs 2009; 18: 627-36.

34. Sessler DI, McGuire J, Sessler AM: Perioperative thermal insulation. Anesthesiology 1991; 74: 875-9.

35. Alderson P, Campbell G, Smith AF, Warttig S, Nicholson A, Lewis SR Thermal insulation for prevention of inadvertent perioperative hypothermia. Cochrane Database Syst Rev 2014; 6: CD009908.

36. Andrzejowski JC, Turnbull D, Nandakumar A, Gowthaman S, Eapen G: A randomised single blinded study of the administration of pre-warmed fluid vs active fluid warming on the incidence of peri-operative hypothermia in short surgical procedures. Anaesthesia 2010; 65: 942-5.

37. Sessler DI: Complications and treatment of mild hypothermia. Anesthesiology 2001; 95: 531-43.

38. Jin Y, Tian J, Sun M, Yang K: A systematic review of randomised controlled trials of the effects of warmed irrigation fluid on core body temperature during endoscopic surgeries. J Clin Nurs 2011; 20: 305-16.

39. Arbeitskreis Kinderanästhesie der DGAI: Die häufigsten Fehler in der Kinderanästhesie. www.ak-kinderanaesthesie.de/files/Celle 2009 Simon_Fehler Kinderanaesthesie.pdf (last accessed on 18 February 2013).

40. Joris J, Banache M, Bonnet F, Sessler DI, Lamy M: Clonidine and ketanserin both are effective treatments for postanesthetic shivering. Anesthesiology 1993; 79: 532-9.

\section{COrresponding author}

Prof. Dr. med. Alexander Torossian

Klinik für Anästhesie und Intensivtherapie,

Universitätsklinikum Gießen und Marburg, Standort Marburg

Baldinger Str. 1, 35043 Marburg, Germany

alexander.torossian@med.uni-marburg.de 


\section{Preventing Inadvertent Perioperative Hypothermia}

Alexander Torossian, Anselm Bräuer, Jan Höcker, Berthold Bein, Hinnerk Wulf, Ernst-Peter Horn

\section{GFIGURE 1}

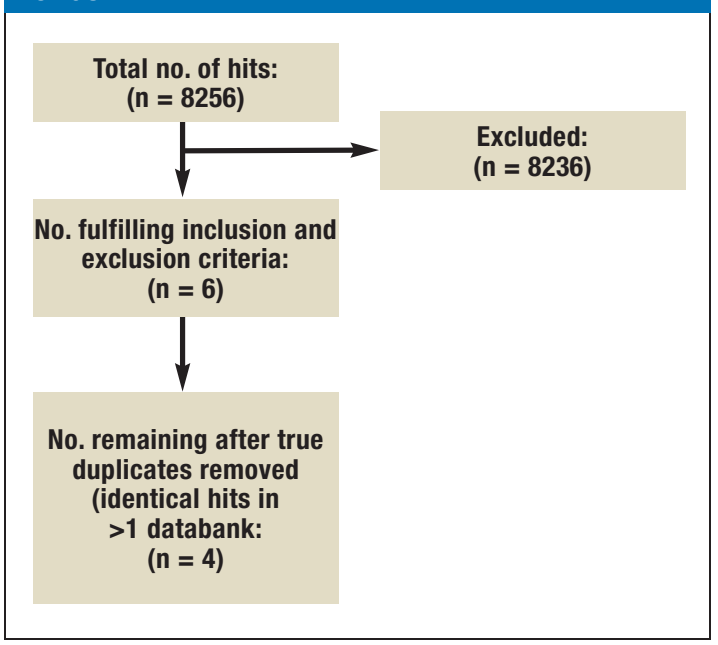

Guideline research for the guideline "Preventing inadvertent perioperative hypothermia"

- NICE guideline 2008 ([3], United Kingdom)—primary source guideline

- Joanna Briggs Institute Guideline 2010 ([4], Australia)

- Canadian and American colleges of surgery 2009 (5)

- ASPAN guideline $2010,2^{\text {nd }}$ ed ([6], USA)

\section{GFIGURE 2}

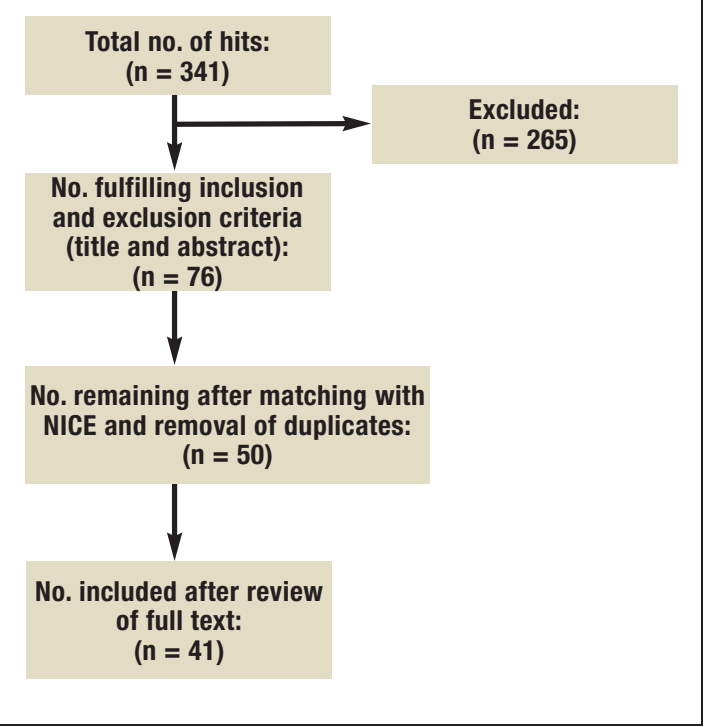

Sample literature search for the section "intraoperative patient warming" for the guideline "Preventing inadvertent perioperative hypothermia"

Search strings:

- "hypothermia" [MeSH Terms] OR "hypothermia"[All Fields]) AND forced-air[All Fields] AND warming[All Fields]: 178 abstracts

- "hypothermia"[MeSH Terms] OR "hypothermia"[All Fields]) AND resistive[All Fields] AND ("heating"[MeSH Terms] OR "heating"[All Fields]): 19 abstracts

- "hypothermia"[MeSH Terms] OR "hypothermia"[All Fields]) AND intraoperative[All Fields] AND warming[All Fields]: 254 abstracts

Number of studies finally remaining for evaluation: 41 